\title{
Introduction to the special issue on three-dimensional underwater acoustics
}

Ying-Tsong Lin, Michael B. Porter, Frédéric Sturm, Marcia J. Isakson, and Ching-Sang Chiu

Citation: The Journal of the Acoustical Society of America 146, 1855 (2019); doi: 10.1121/1.5126013

View online: https://doi.org/10.1121/1.5126013

View Table of Contents: https://asa.scitation.org/toc/jas/146/3

Published by the Acoustical Society of America

\section{ARTICLES YOU MAY BE INTERESTED IN}

Beam tracing for two- and three-dimensional problems in ocean acoustics

The Journal of the Acoustical Society of America 146, 2016 (2019); https://doi.org/10.1121/1.5125262

3D acoustic propagation through an estuarine salt wedge at low-to-mid-frequencies: Modeling and measurement The Journal of the Acoustical Society of America 146, 1888 (2019); https://doi.org/10.1121/1.5125258

Multiscale multiphysics data-informed modeling for three-dimensional ocean acoustic simulation and prediction The Journal of the Acoustical Society of America 146, 1996 (2019); https://doi.org/10.1121/1.5126012

Three-dimensional global scale underwater sound modeling: The T-phase wave propagation of a Southern MidAtlantic Ridge earthquake

The Journal of the Acoustical Society of America 146, 2124 (2019); https://doi.org/10.1121/1.5126010

Measurements and modeling of acoustic propagation in a scale model canyon

The Journal of the Acoustical Society of America 146, 1858 (2019); https://doi.org/10.1121/1.5125130

Three-dimensional boundary fitted parabolic-equation model of underwater sound propagation

The Journal of the Acoustical Society of America 146, 2058 (2019); https://doi.org/10.1121/1.5126011

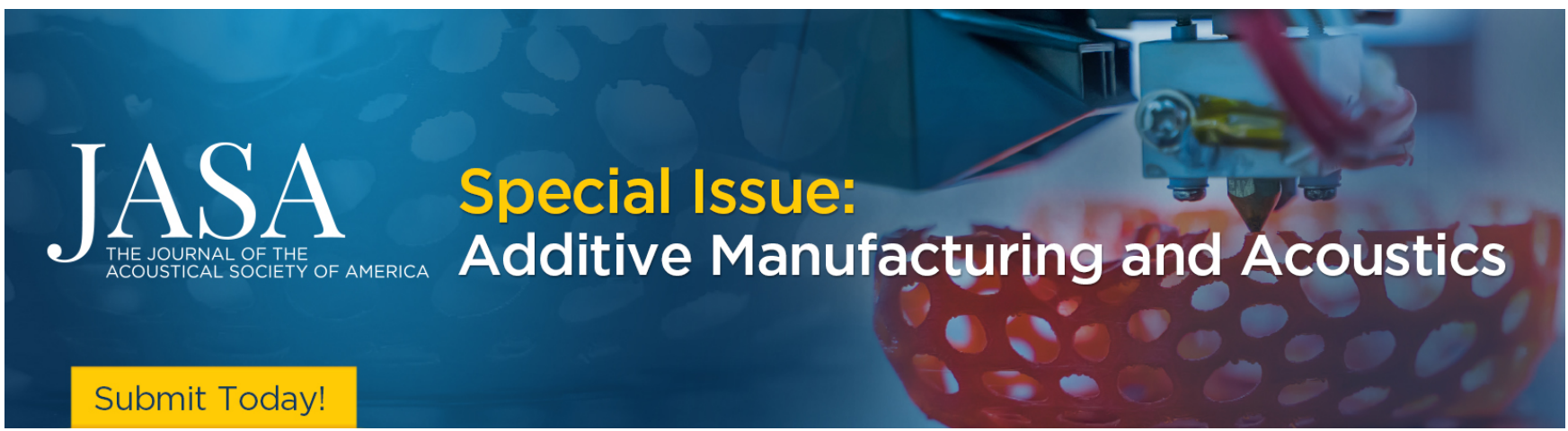




\title{
Introduction to the special issue on three-dimensional underwater acoustics
}

\author{
Ying-Tsong Lin ${ }^{\mathrm{a})}$ \\ Applied Ocean Physics and Engineering Department, Woods Hole Oceanographic Institution, Woods Hole, \\ Massachusetts 02543, USA \\ Michael B. Porter \\ Heat, Light, and Sound Research, Inc., San Diego, California 92130, USA \\ Frédéric Sturm \\ Laboratoire de Mécanique des Fluides et d'Acoustique (LMFA), Centre Acoustique, Ecole Centrale de Lyon, \\ Écully 69134, France \\ Marcia J. Isakson \\ Applied Research Laboratories, The University of Texas at Austin, Austin, Texas 78713, USA \\ Ching-Sang Chiu \\ Department of Oceanography, Naval Postgraduate School, Monterey, California 93943, USA
}

(Received 21 August 2019; accepted 22 August 2019; published online 1 October 2019)

https://doi.org/10.1121/1.5126013

[JFL]

Pages: $1855-1857$

\section{INTRODUCTION}

This special issue focuses on compelling three-dimensional (3D) volumetric and boundary effects on underwater sound propagation and scattering in complex and time-varying (thus four-dimensional) underwater environments. It consists of 24 papers covering analytical, numerical, and experimental studies and presents a collection of up-to-date research on this active and relevant topic.

Underwater 3D acoustic effects caused by reflection, refraction, diffraction, and/or scattering of sound energy in both vertical and horizontal planes have been observed and investigated extensively for many decades. A textbook by Lee and Schultz (1995) and a review article by Tolstoy (1996) provided an excellent summary of 3D acoustic research and different modeling techniques up to the 1990s. The research on $3 \mathrm{D}$ effects continued in the following years, and many efficient and effective numerical models were developed, e.g., Smith (1999), Sturm and Fawcett (2003), and Heaney and Campbell (2016). In addition, experimental evidence of 3D propagation was also shown, e.g., Frank et al. (2005), Heaney and Murray (2009), and Lynch et al. (2010). The readers are referred to the citations of these listed papers for complete references.

Many physical oceanographic and marine geological features can cause significant $3 \mathrm{D}$ acoustic effects. To capture the most profound features for analyzing the underlying propagation and scattering physics, many idealized benchmark problems were proposed, the most important of which is the 3D wedge problem studied by Bradley and Hudimac (1970), Buckingham (1987), Deane and Buckingham (1993), and others. In this special issue, Lee et al. (2019a,b), Lin (2019), Petrov and Petrov (2019), Porter (2019), and Sagers and

\footnotetext{
${ }^{\text {a)} E l e c t r o n i c ~ m a i l: ~ y t l i n @ w h o i . e d u ~}$
}

Ballard (2019) utilize the 3D wedge problem to demonstrate and verify numerical and scale models. In addition to the wedge problem, other idealized cases that study waveguide parameter sensitivity and ambient noise distribution and correlation can be found in this issue. These include Gaussianshaped canyons (Barclay and Lin, 2019; Lee et al., 2019b), double seamounts (Porter, 2019), curved nonlinear internal wave ducts (Milone et al., 2019), circular slopes (Katsnelson and Petrov, 2019), and slope fronts (DeCourcy et al., 2019).

Besides idealized cases, many papers in this special issue consider realistic environments, such as estuaries (Reeder and Lin, 2019) and lakes (Sagers et al., 2019), the Hudson Canyon (Ballard and Sagers, 2019; Barclay and Lin, 2019), the East China Sea (Porter, 2019), nonlinear internal waves (Dossot et al., 2019; Duda et al., 2019), the continental slope (Dall'Osto, 2019), the Mid-Atlantic Ridge (Oliveira and Lin, 2019), the abyssal seafloor (Stephen et al., 2019), and even bubble nets produced by foraging humpback whales (Qing et al., 2019). These studies indeed provide useful insights to the understanding of 3D acoustic effects observed in the real world, such as time-varying features caused by salt wedges in estuaries and nonlinear internal waves in the continental shelf area, as well as bathymetric effects on 3D focusing, defocusing, and diffraction.

The ability of numerical models to generate accurate predictions of $3 \mathrm{D}$ acoustic propagation and scattering is also highlighted in this special issue. These models include finiteelement methods by Qing et al. (2019) to calculate acoustic pressure and particle motion induced by foraging whale vocalizations inside the bubble net, and by Lecoulant et al. (2019) to calculate seismo-acoustic propagation in the ocean and seabed generated by earthquakes. Another group of numerical models uses the parabolic-equation method, which was first introduced to underwater acoustics by Hardin and Tappert (1973) and Tappert (1974). Papers by 
Ivansson (2019), Lee et al. (2019a,b), and Lin (2019) focus on handling higher-order cross terms resulting from the square-root Helmholtz operator splitting, while Lin (2019) discusses using a boundary-fitted grid to better handle boundary effects. Also for 3D sound propagation modeling, Porter (2019) extends the beam tracing method and demonstrates its 3D capability with several benchmark problems and a realistic East China Sea example. To improve the prediction accuracy of sound propagation within realistic internal waves, Duda et al. (2019) introduce a joint modeling framework to incorporate a nonlinear internal wave model nested in a tide-inclusive data-assimilating regional model. There are three scattering models presented in this issue, including a fully explicit marching-on-in-time scheme to solve the time domain Kirchhoff integral equation by Chen et al. (2019), the transient equivalent source method for broadband scattering computations by Fahnline (2019), and a numerical Green's function method to calculate the farfield scattering from objects resting on or buried within the sea floor by Gunderson et al. (2019).

Two scale-model tank experiments for 3D sound propagation and scattering by Ballard and Sagers (2019) and Sagers and Ballard (2019) are reported in this issue. With wellcontrolled laboratory environments and repetitive samples, these tank studies produce high quality data to validate numerical computations. In addition to tank experiments, this issue has papers on real-world data and field experiments, including (1) acoustic data sets collected during the Shallow Water 2006 experiment showing 3D sound propagation effects of nonlinear internal waves (Dossot et al., 2019), and the T-phase wave propagation of a submarine earthquake from the Southern Mid-Atlantic Ridge to the New-Jersey Continental Shelf (Oliveira and Lin, 2019), (2) a 3D sound propagation experiment at the Columbia River estuary for studying acoustic effects of estuarine salt wedges (Reeder and Lin, 2019), (3) the observational evidence of out-of-plane ambient noise in Lake Travis (Sagers et al., 2019), and (4) the Ocean Bottom Seismometer Augmentation in the North Pacific Experiment showing 3D bottom diffraction on the abyssal seafloor (Stephen et al., 2019). Besides the physical effects, the 3D acoustic impacts on source localization and signal processing have long been recognized and shown in experimental data (e.g., Ballard, 2013). In this special issue, Dall'Osto (2019) employs hydroacoustic data collected by the global International Monitoring System of the Comprehensive Nuclear-Test-Ban Treaty Organization to demonstrate how $3 \mathrm{D}$ propagation features can be used in source triangulation on a basin scale.

Finally, as Guest Editors, we would like to express our sincere appreciation to the JASA editorial staff for their assistance in producing this special issue. We would also like to thank the Editor-in-Chief, James Lynch, for his encouragement, guidance, and advice. Our thanks also go to the reviewers and Associate Editors who reviewed the papers and provided valuable comments for improvement. Most importantly, we would like to extend our appreciation to all of the special issue authors who contributed high quality manuscripts that clearly display and demonstrate the breadth of the ongoing 3D acoustic research.
Ballard, M. S. (2013). "Estimation of source range using horizontal multipath in continental shelf environments," J. Acoust. Soc. Am. 134(4), EL340-EL344.

Ballard, M. S., and Sagers, J. D. (2019). "Measurements and modeling of acoustic propagation in a scale model canyon," J. Acoust. Soc. Am. 146(3), 1858-1866.

Barclay, D. R., and Lin, Y.-T. (2019). "Three-dimensional ambient noise modeling in a submarine canyon," J. Acoust. Soc. Am. 146(3), 1956-1967.

Bradley, D. L., and Hudimac, A. A. (1970). "The propagation of sound in a wedge shaped shallow water duct," Technical Report NOLTR 70-325, Naval Ordinance Laboratory, Silver Spring, MD.

Buckingham, M. J. (1987). "Theory of three dimensional acoustic propagation in a wedgelike ocean with a penetrable bottom," J. Acoust. Soc. Am. 82(1), 198-210.

Chen, R., Sayed, S. B., Alharthi, N., Keyes, D., and Bagci, H. (2019). “An explicit marching-on-in-time scheme for solving the time domain Kirchhoff integral equation,” J. Acoust. Soc. Am. 146(3), 2068-2079.

Dall'Osto, D. (2019). "Source triangulation utilizing 3D arrivals: Application to the search for the ARA San Juan submarine," J. Acoust. Soc. Am. 146(3), 2104-2112.

Deane, G. B., and Buckingham, M. J. (1993). "An analysis of the threedimensional sound field in a penetrable wedge with a stratified fluid or elastic basement," J. Acoust. Soc. Am. 93(3), 1319-1328.

DeCourcy, B. J., Lin, Y.-T., and Siegmann, W. L. (2019). "Effects of front width on acoustic ducting by a continuous curved front over a sloping bottom," J. Acoust. Soc. Am. 146(3), 1923-1933.

Dossot, G. A., Smith, K. B., Badiey, M., Miller, J. H., and Potty, G. R. (2019). "Underwater acoustic energy fluctuations during strong internal wave activity using a three-dimensional parabolic equation," J. Acoust. Soc. Am. 146(3), 1875-1887.

Duda, T. F., Lin, Y.-T., Newhall, A. E., Helfrich, K. R., Lynch, J. F., Zhang, W. G., Lermusiaux, P. F. J., and Wilkin J. (2019). "Multiscale multiphysics data-informed modeling for three-dimensional ocean acoustic simulation and prediction,” J. Acoust. Soc. Am. 146(3), 1996-2015.

Fahnline, J. B. (2019). "Efficient, wide-band rigid-body and elastic scattering computations using transient equivalent sources," J. Acoust. Soc. Am. 146(3), 2080-2092.

Frank, S. D., Badiey, M., Lynch, J. F., and Siegmann, W. L. (2005). "Experimental evidence of three-dimensional acoustic propagation caused by nonlinear internal waves," J. Acoust. Soc. Am. 118(2), 723-734.

Gunderson, A. M., Isakson, M. J., and Bonomo, A. L. (2019). "Method of numerical Green's function determination for far-field scattering solutions from objects at a water-sediment interface," J. Acoust. Soc. Am. 146(3), 2093-2103.

Hardin, R. H., and Tappert, F. D. (1973). "Applications of the split-step Fourier method to the numerical solution of nonlinear and variable coefficient wave equations," SIAM Rev. 15, 423.

Heaney, K. D., and Campbell, R. L. (2016). "Three-dimensional parabolic equation modeling of mesoscale eddy deflection," J. Acoust. Soc. Am. 139(2), 918-926.

Heaney, K. D., and Murray, J. J. (2009). "Measurements of threedimensional propagation in a continental shelf environment," J. Acoust. Soc. Am. 125(3), 1394-1402.

Ivansson, S. (2019). "Local accuracy of cross-term corrections of threedimensional parabolic-equation models," J. Acoust. Soc. Am. 146(3), 2030-2040.

Katsnelson, B. G., and Petrov, P. S. (2019). "Whispering gallery waves localized near circular isobaths in shallow water," J. Acoust. Soc. Am. 146(3), 1968-1981.

Lecoulant, J., Guennou, C., Guillon, L., and Royer, J.-Y. (2019). “Threedimensional-modeling of earthquake generated acoustic waves in the ocean in simplified configurations," J. Acoust. Soc. Am. 146(3), 2113-2123.

Lee, D., and Schultz, M. H. (1995). Numerical Ocean Acoustic Propagation in Three Dimensions (World Scientific, Singapore).

Lee, K., Seong, W., and Na, Y. (2019a). "Three-dimensional Cartesian parabolic equation model with higher-order cross-terms using operator splitting, rational filtering, and split-step Padé algorithm," J. Acoust. Soc. Am. 146(3), 2041-2049.

Lee, K., Seong, W., and Na, Y. (2019b). "Split-step Padé solver for threedimensional Cartesian acoustic parabolic equation in stair-step representation of ocean," J. Acoust. Soc. Am. 146(3), 2050-2057. 
Lin, Y.-T. (2019). "Three-dimensional boundary fitted parabolic-equation model of underwater sound propagation," J. Acoust. Soc. Am. 146(3), 2058-2067.

Lynch, J. F., Lin, Y.-T., Duda, T. F., and Newhall, A. E. (2010). "Acoustic ducting, shadowing, refraction and dispersion by curved non-linear internal waves in shallow water," IEEE J. Ocean. Eng. 35(1), 12-27.

Milone, M. A., DeCourcy, B. J., Lin, Y.-T., and Siegmann, W. L. (2019). "Parameter dependence of acoustic mode quantities in an idealized model for shallow-water nonlinear internal wave ducts," J. Acoust. Soc. Am. 146(3), 1934-1945.

Oliveira, T. C., and Lin, Y.-T. (2019). "Three-dimensional global scale underwater sound modeling: The T-phase wave propagation of a Southern Mid-Atlantic Ridge earthquake," J. Acoust. Soc. Am. 146(3), 2124-2135.

Petrov, P. N., and Petrov, P. S. (2019). "Asymptotic solution for the problem of sound propagation in a shallow sea with the bathymetry described by a parametric quadratic function," J. Acoust. Soc. Am. 146(3), 1946-1955.

Porter, M. B. (2019). "Beam tracing for two- and three-dimensional problems in ocean acoustics," J. Acoust. Soc. Am. 146(3), 2016-2029.

Qing, X., White, P. R., Leighton, T. G., Liu, S., Qiao, G., and Zhang, Y.

(2019). "Three-dimensional finite element simulation of acoustic propagation in spiral bubble net of humpback whale," J. Acoust. Soc. Am. 146(3), 1982-1995.

Reeder, D. B., and Lin Y.-T. (2019). "3D acoustic propagation through an estuarine salt wedge at low-to-mid-frequencies: Modeling and measurement," J. Acoust. Soc. Am. 146(3), 1888-1902.

Sagers, J. D., and Ballard, M. S. (2019). "Scale model observations of coupled vertical modes in a translationally invariant wedge," J. Acoust. Soc. Am. 146(3), 1867-1874.

Sagers, J. D., Lenhart, R. D., and Ballard, M. S. (2019). "Observation of out-of-plane ambient noise on two vector sensor moorings in Lake Travis," J. Acoust. Soc. Am. 146(3), 1903-1912.

Smith, K. B. (1999). "A three-dimensional propagation algorithm using finite azimuthal aperture," J. Acoust. Soc. Am. 106(6), 3231-3239.

Stephen, R. A., Bolmer, S. T., Worcester, P. F., Dzieciuch, M. A., and Udovydchenkov, I. A. (2019). "Three-dimensional bottom diffraction in the North Pacific,” J. Acoust. Soc. Am. 146(3), 1913-1922.

Sturm, F., and Fawcett, J. A. (2003). "On the use of higher-order azimuthal schemes in 3-D PE modeling," J. Acoust. Soc. Am. 113(6), 3134-3145.

Tappert, F. D. (1974). "Parabolic equation method in underwater acoustics," J. Acoust. Soc. Am. 55, S34.

Tolstoy, A. (1996). "3-D propagation issues and models," J. Comput. Acoust. 4, 243-271. 